\title{
High-strength fluoroanhydrite composition
}

\author{
Grigory Yakovlev ${ }^{1}$, Jadvyga Keriene ${ }^{2}$, Valery Grakhov ${ }^{3}$, Rostislav Drochytka ${ }^{4}$, \\ Anastasiya Gordina ${ }^{5}$, Anatoly Pichugin ${ }^{6}$, Kirill Bazhenov ${ }^{7}$, Viktoriya Troshkova ${ }^{8}$ \\ 1, 3, 5, 7, 8 Kalashnikov Izhevsk state technical university, Izhevsk, Russia \\ ${ }^{2}$ Vilnius Gediminas Technical University, Vilnius, Lithuania \\ ${ }^{4}$ Brno University of Technology, Brno, Czech Republic \\ ${ }^{6}$ Novosibirsk State Agrarian University, Novosibirsk, Russia \\ E-mail: 'Igyakov@istu.ru (correspondingauthor)
}

\begin{abstract}
The research studies the properties of a high-strength anhydrite composition based on fluoroanhydrite, a waste product of hydrofluoric acid. To activate fluoranhydrite, Na3PO4 sodium phosphate was added to the composition in an amount of $3 \%$ of the mass. The physico-chemical studies of the structure and properties of activated fluoroanhydrite conducted using infrared spectroscopy and X-ray phase analysis showed changes in the composition of the hardened composite, and the study of the fluoroanhydrite microstructure revealed the formation of a denser matrix with the increased strength. An increase in the water resistance of the developed binder matrix was noted. The composition can be used as a cheap substitute for gypsum plaster due to the low prime cost of raw materials, and also contribute to the improvement of the environmental situation in fluoroanhydrite disposal sites.
\end{abstract}

Keywords: Fluoroanhydrite, activator, sodium phosphate, calcium phosphate, calcium sulfate dehydrate, ultrafine new formations.

\section{Introduction}

One of the main tasks for construction materials science is to study the possibility of the utilization of chemical industry waste in the production of construction materials. Recycling secondary raw materials reduces the damage caused to nature in disposal sites for raw materials, and significantly decreases the production cost of new construction materials (Belov et al., 2012; Volzhensky, Burov, \& Kolokolnikov, 1979; Budnikov \& Zorin, 1954).

Anhydrite mortars and concrete along with those based on gypsum have a number of positive properties, including strength, short setting time, the possibility of regulating the humidity of premises due to the porous structure of the composite, and ecological friendliness (Nowak, Wutz, Prosiegel, \& Fischer, 2006). Chemical and mineralogical composition of fluoroanhydrite makes it more cost-effective for the mass production of materials based on anhydrite binders comparing to natural or thermally treated anhydrite (Vlad, Zouaoui, Kambia, \& Plank, 2006).

Industrial application of anhydrite compositions that start setting in 8-10 hours without adding chemical admixtures is limited with some factors including the low rate of setting and hardening. Therefore, the possibility of producing a composition based on fluoroanhydrite, a waste product of hydrofluoric acid, requires accelerating the processes of structure formation (Lushnikova, Ruzina, Gordina, \& Polyanskih, 2016; Plekhanova, Keriene, Gailius, \& Yakovlev, 2007; El Hajjouji \& \& Murat, 1989).

Production of hydrofluoric acid from 1 ton of calcium fluoride $\left(\mathrm{CaF}_{2}\right)$ and 1.25 tons of sulfuric acid gives 0.5 tons hydrofluoric acid and 1.7 tons finely dispersed dry anhydrite.

$$
\mathrm{CaF}_{2}+\mathrm{H}_{2} \mathrm{SO}_{4} \rightarrow \mathrm{CaSO}_{4}+2 \mathrm{HF} .
$$

Annually, 2-3 million tons of anhydrite are produced by this method worldwide. However, it is only used partially (Belov et al., 2012). Therefore, the developments and implementation of technologies of industrial anhydrite binders and materials based on them are considered as relevant.

To improve the physical and technical properties of anhydrite materials, hardening activators are widely used (Vtorov, Fischer, \& Stark, 2000; Grimme, 1962). They accelerate the dissolving of fluoroanhydrite after mixing with water, which in turn leads to the acceleration of hydration and hardening of the binder (Leškevičiene \& Nizevičiene, 2014; Ottemann, 1951). Basically, for activating the processes of binder structuring, various hardening activators are 
used, which are classified by the activation method as sulphate, alkaline and combined activators (Altmann, 1993; Fischer \& Vtorov, 2000). Using alkaline activators provides the constant volume of material. As a result, the consumption of material reduces, and the setting speed, strength and durability of the product increase (Vtorov \& Fisher, 2001). Sodium phosphate $\mathrm{Na}_{3} \mathrm{PO}_{4}$ is rarely used as a fluoroanhydrite activator.

\section{Materials and methods}

To study the binding properties, powdered fluoroanhydrite meeting TS 5744-132-05807960-98 (1998) and produced by "GaloPolymer" was used. In order to increase the activity of the man-made material, it was re-milled in an ID-200 disk mill.

The conducted dispersion analysis of the ground fluoranhydrite showed that the average particle diameter is $10.5 \mu \mathrm{m}$ (see Figure 1). It should be noted that the composition of fluoranhydrite has a nanodisperse component with an average particle size of $140 \mathrm{~nm}$.

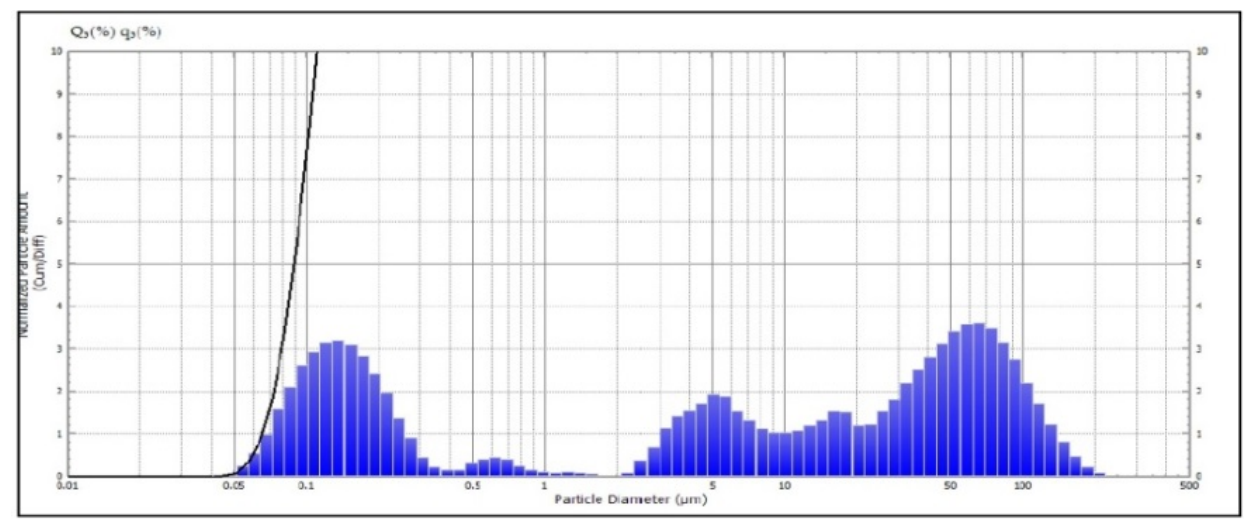

Figure 1. Dispersion analysis of ground fluoranhydrite

The chemical composition of fluoranhydrite, in \%, is $\mathrm{CaO}-35.0-36.5 ; \mathrm{SO}_{3}$-not less than 45; $\mathrm{CaF}_{2}-2.2-5$; $\mathrm{SiO}_{2}-2.6-3.4 ; \mathrm{Al}_{2} \mathrm{O}_{3}-0.5-0.7 ; \mathrm{Fe}_{2} \mathrm{O}_{3}-0.2-0.95$ (TS 5744-132-05807960-98).

The X-ray phase analysis of fluoroanhydrite showed that in its composition, soluble calcium sulfate prevails $\gamma$ - $\mathrm{CaSO}_{4}$ (see Figure 2a). The X-ray diffractogram of fluoroanhydrite shows reflections corresponding to soluble anhydrite $\gamma-\mathrm{CaSO}_{4}\left(\mathrm{~d}_{\alpha}=3.50 ; 2.85 ; 2.33 ; 2.21 ; 1.87 \AA\right)$; there are weak reflections of calcium sulfate dehydrate $\mathrm{CaSO}_{4} \cdot 2 \mathrm{H}_{2} \mathrm{O}\left(\mathrm{d}_{\alpha}=7.55 ; 4.26 ; 2.85 \AA\right)$, silicon oxide $\mathrm{SiO}_{2}\left(\mathrm{~d}_{\alpha}=3.35 \AA\right)$, calcite $\mathrm{CaCO}_{3}\left(\mathrm{~d}_{\alpha}=3.03 \AA\right)$.

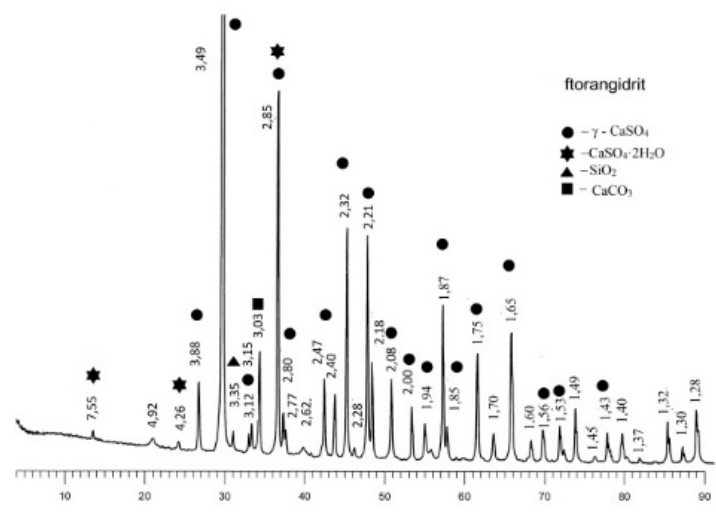

a)

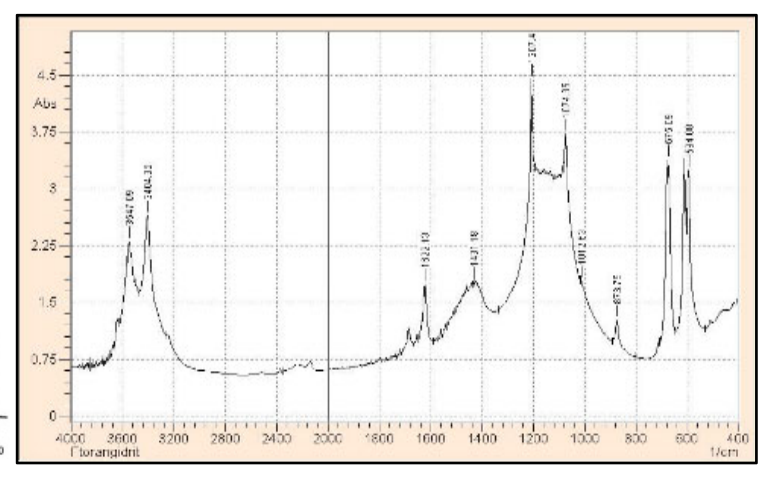

b)

Figure 2. X-ray diffractogram (a) and IR-spectrum (b) of fluoroanhydrite

IR spectroscopy of fluoroanhydrite conducted on a FT-IR IRAffinity-1 spectrometer in a frequency range of $4000 \div 400 \mathrm{~cm}^{-1}$ (see Figure $2 \mathrm{~b}$ ) showed the presence of absorption bands with wave numbers that cause the presence of the following groups:

- absorption in the frequency range 3400-3600 $\mathrm{cm}^{-1}$ associated with symmetric and asymmetric stretching vibrations of $\mathrm{OH}$ groups;

- two absorption bands in the interval $1600-1700 \mathrm{~cm}^{-1}$ associated with deformation vibrations of $\mathrm{OH}$ groups; 
-absorption bands in the interval $1130-1080,610-680 \mathrm{~cm}^{-1}$ can be seen associated with $\mathrm{SO}_{4}{ }^{2-}$;

- the absorption bands in the interval $1420-1430$ and $873.75 \mathrm{~cm}^{-1}$, are due to $\mathrm{CO}_{3}{ }^{2-}$.

The mechanical research of materials based on hardening fluoroanhydrite were carried out on a PGM-100MG4 press in accordance with GOST 8462-85 (1985) and GOST 23789-79 (1979).

To accelerate the processes of structure formation and increase the physical and mechanical characteristics of the man-made product, a hardening activator, sodium phosphate, was used in the composition.

$\mathrm{X}$-ray phase analysis was conducted on a general DRON-3 diffractometer in the Bragg-Brentano focusing re-

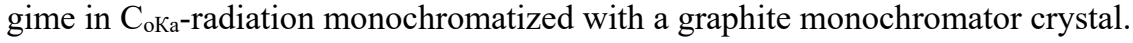

The microstructure of the obtained composition was performed on a MIRA3 TESCAN microscope at the AdMaS research center of the Technical University of Brno.

\section{Results and discussion}

Mechanical characteristics of materials based on hardening fluoroanhydrite are determined by a number of physical and chemical processes occurring during hydration of anhydrous calcium sulfate. The study of the binding properties of fluoroanhydrite showed that when it is mixed with water, the compressive strength is up to $20 \mathrm{MPa}$ at the age of 28 days.

The preliminary optimization of fluoroanhydrite-based compositions on the strength, the content of aqueous solution of $\mathrm{Na}_{3} \mathrm{PO}_{4}$ varying from $2 \%$ to $5 \%$, showed that the optimal concentration is $3 \%$. Exceeding this concentration leads to efflorescence on the surface of the hardened material, but at the same time, its strength increases. The optimal combination of the components of the fluoroanhydrite composition provides an increase in the compressive and bending strength of up to 40 and $10 \mathrm{MPa}$, respectively (see Figure 3).

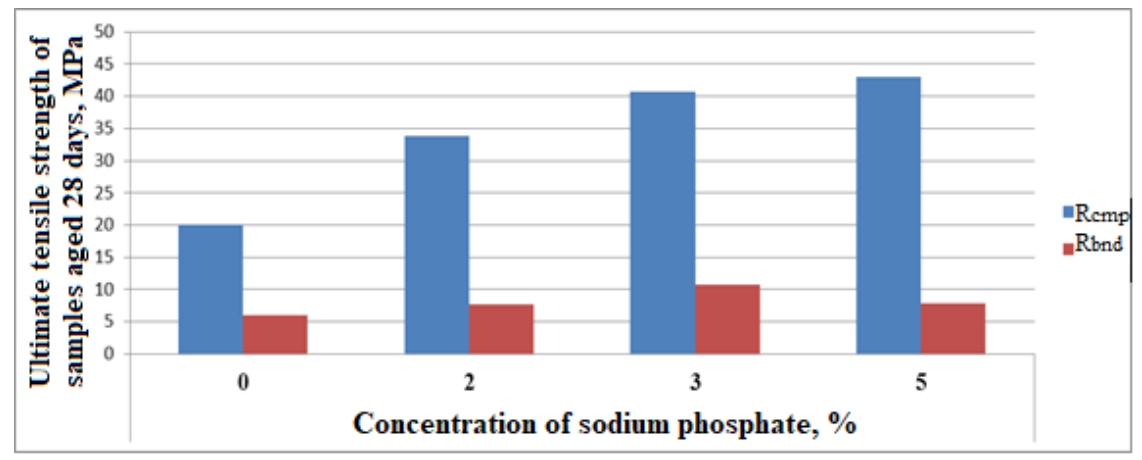

Figure 3. Dependence of the ultimate tensile strength of the samples on the activator concentration

While determining the setting time for the check and modified compositions in accordance with GOST 23789-79, the final set of the check sample was found to be 23 hours. Samples with an activator based on an aqueous solution of sodium phosphate harden after 4 hours.
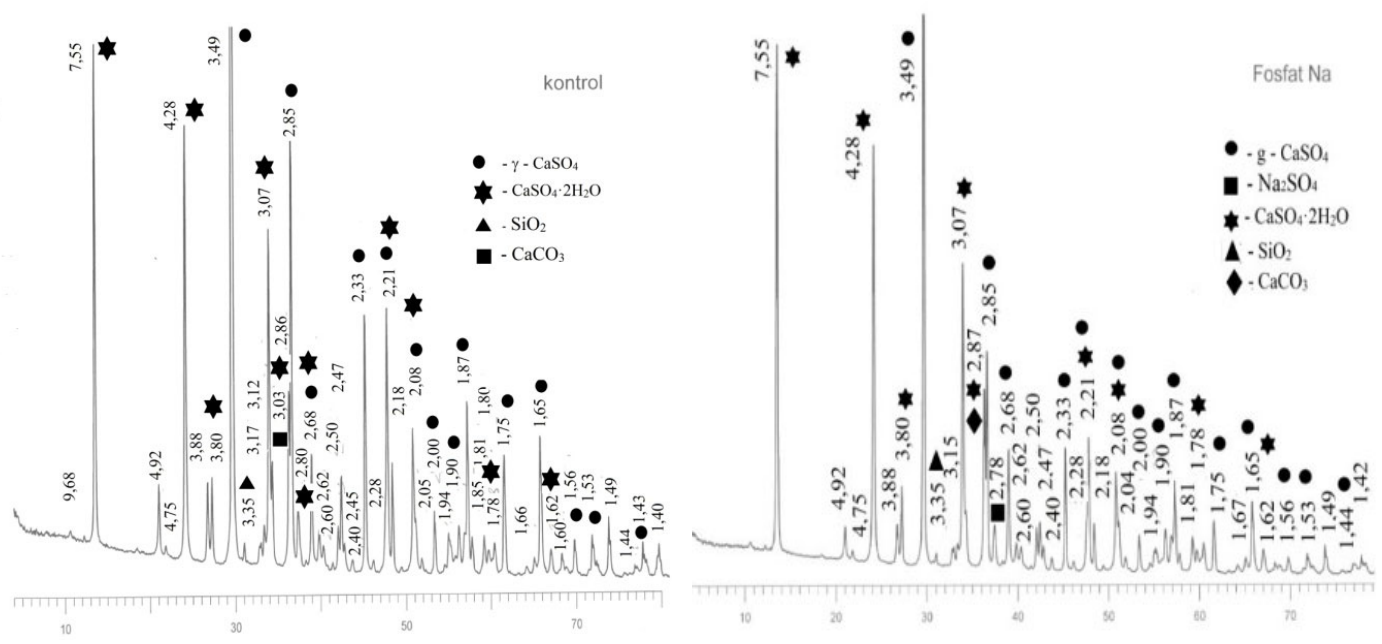

Figure 4. X-ray diffractograms of the samples without activator (a) and activated with $3 \%$ aqueous solution of $\mathrm{Na}_{3} \mathrm{PO}_{4}(\mathrm{~b})$, after hardening for 7 days 
Thus, adding sodium phosphate to fluoroanhydrite provides an increase in the strength of the binding matrix by a factor of 2. To confirm the mechanism of sodium phosphate influence and to study the structure of the activated composite, modern methods of physical and chemical analysis were used, including X-ray phase, IR spectral and microstructural analyses.

The X-ray diffraction pattern of fluoroanhydrite (see Figure 4a) mixed with water without the activator showed that calcium sulfate dihydrate $\mathrm{CaSO}_{4} \cdot 2 \mathrm{H}_{2} \mathrm{O}$ prevails in the composition of the hydration products, but there is also a significant amount of non-hydrated $\gamma-\mathrm{CaSO}_{4}$.

The X-ray diffraction pattern (see Figure $4 \mathrm{~b}$ ) of the activated fluoroanhydrite composition shows a significant increase in the content of calcium sulfate dihydrate (an increase in the intensity of its reflection lines) in comparison with the check sample. Also there is an insignificant amount of silicon oxide, calcium carbonate, and traces of sodium sulfate, which also contributes to the activation of fluoroanhydrite (GOST 23789-79, 1979).

The IR spectroscopy of the check composition (see Figure 5a) and the composition with a $3 \% \mathrm{Na}_{3} \mathrm{PO}_{4}$ activator content (see Figure 5b) were also performed. The analysis of the results of infrared spectroscopy confirmed the presence of the found by X-ray phase analysis compounds in the set compositions.

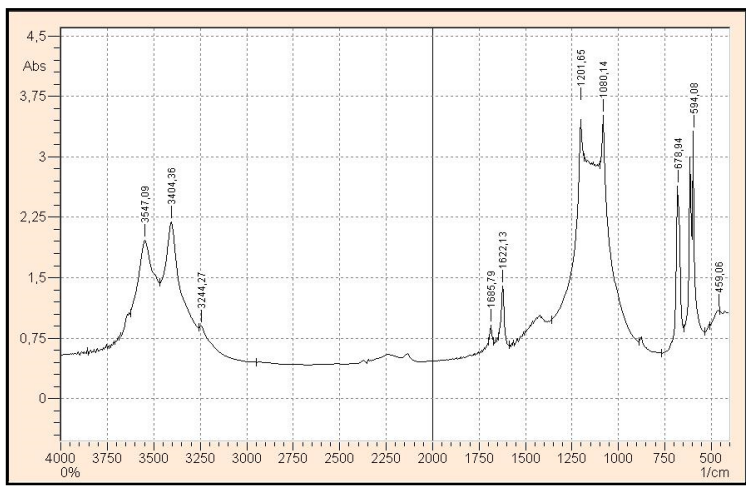

a)

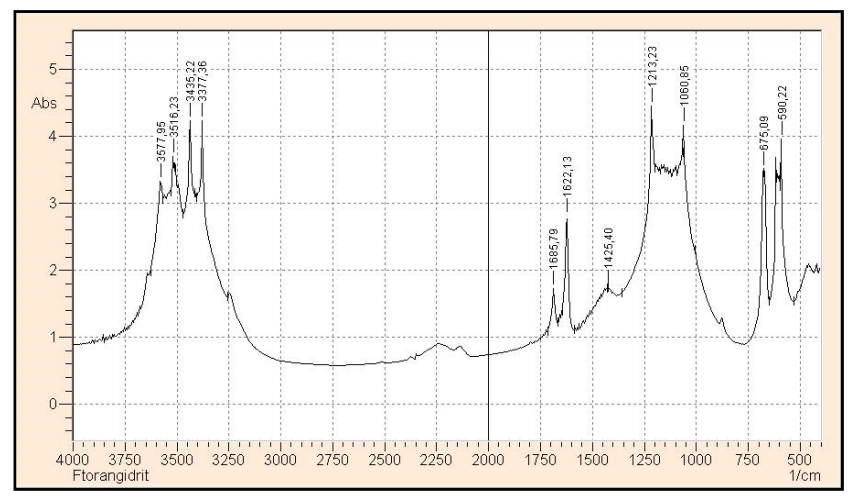

b)

Figure 5. IR spectra of samples after hardening for 7 days: a) without activator;

b) activated with $3 \%$ aqueous solution of $\mathrm{Na}_{3} \mathrm{PO}_{4}$

At the same time, sodium phosphate being added into the fluoroanhydrite composition (see Figure 5b), the analysis of the IR spectra of the samples showed the changes of frequency (by $1201.65 \mathrm{~cm}^{-1}$ to $1213.23 \mathrm{~cm}^{-1}$ and by $1080.14 \mathrm{~cm}^{-1}$ to $1060.85 \mathrm{~cm}^{-1}$ ) shifts, which are associated with a change in the environment around the SO42- group and the formation of a complex compound including the group $\mathrm{PO}_{4}{ }^{3-}$, by analogy with the studies of the authors (Leškevičienè \& Nizevičienè, 2014; Jakowlew \& Keriene, 2000). This assumption is confirmed by a change in the absorption lines and the formation of new lines in the frequency range $3300-300 \mathrm{~cm}^{-1}$. They are due to the fact that the admixture takes a direct part in the formation of crystalline hydrates in the structure of the forming gypsum rock.

Thus, the results of the conducted X-ray phase and IR spectral analyses studies lead to the conclusion that the activation of the setting of fluoroanhydrite by sodium phosphate creates favorable conditions for its hydration and setting.

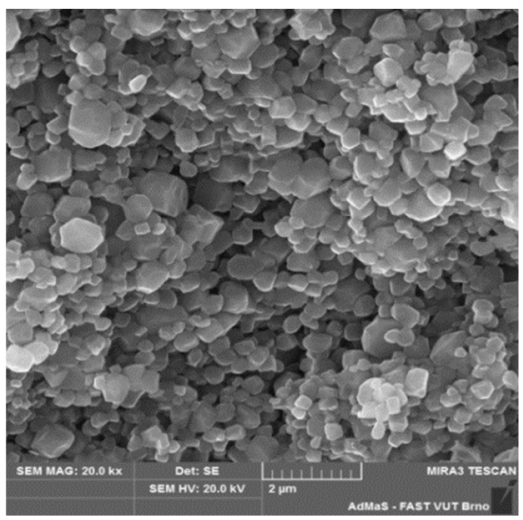

a)

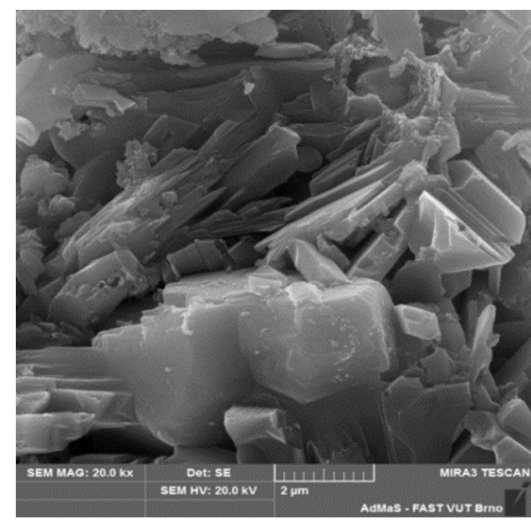

b)

Figure 6. The microstructure of fluoroanhydrite after hardening for 7 days without $\mathrm{Na}_{3} \mathrm{PO}_{4}:$ (a) - non-hydrated fluoroanhydrite granules; (b) - blocks of crystals of gypsum in the binding matrix of the fluoroanhydrite composition 
The study of the microstructure of the obtained composition showed that the structure of the fluoroanhydrite composition after hardening for 7 days without using 3\% sodium phosphate solution (see Figure 6a) is characterized by blocks of plate-like gypsum crystals. There are also fragments of non-hydrated fluoroanhydrite with weakly bound particles of non-hydrated fluoroanhydrite, forming a loose structure consisting of cuboid and tetragonal crystals that have weak bonds with each other (see Figure $6 \mathrm{~b}$ ).

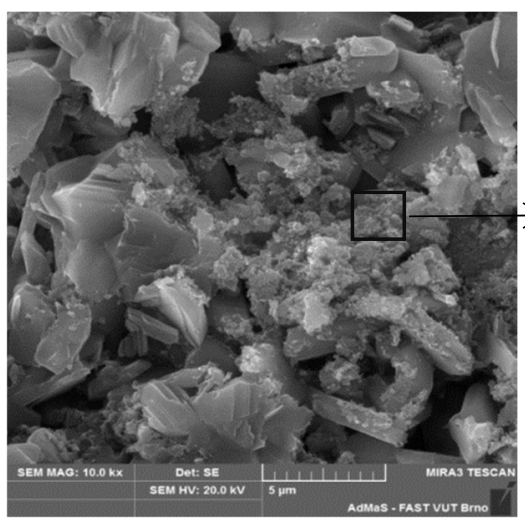

a)

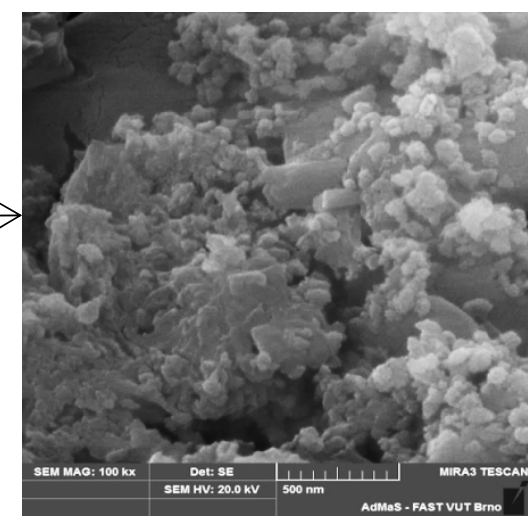

b)

Figure 7. The microstructure of hardened fluoroanhydrite activated with $3 \%$ aqueous solution of $\mathrm{Na}_{3} \mathrm{PO}_{4}(\mathrm{a})$, a fragment of the microstructure with nanometer size new formations on the surface of the crystals of two-water gypsum (b)

With the introduction of an activator into the composition of fluoroanhydrite, a more dense structure is formed (see Figure 7), which is characterized by compaction of intercrystalline pores with ultradisperse neoplasms with sizes of 50-100 nm (see Figure 7b), which additionally bind calcium hydrate calcium sulfate. Thus, the morphology of the developed anhydrite material in comparison with the control composition has a more dense packing of hydration products, which leads to an increase in the strength of activated fluoroanhydrite. In this case, as can be seen from the Table 1, the water absorption of the fluoroanhydrite composition decreases and its water resistance increases.

Table 1. Results of water-resistance tests

\begin{tabular}{|c|c|c|}
\hline Composition & Water absorption, W & Softening coefficient, Cs \\
\hline Check & $10.37 \%$ & 0.51 \\
\hline Activated & $5.62 \%$ & 0.71 \\
\hline
\end{tabular}

The analysis of hardened fluoroanhydrite activated with sodium phosphate kept in water for 24 hours showed (Table 1) that the softening coefficient was $\mathrm{Cs}=0.71$, which is higher than the one for calcium sulfate dihydrate $\mathrm{Cs}=0.4$.

Thus, adding a hardening activator of a 3\%-aqueous solution of sodium phosphate accelerates the processes of structure formation as well as contributes to the formation of a denser matrix structure, which ultimately provides a high-strength fluoroanhydrite-based material with higher water resistance, which is characterized with a shorter setting time than traditional anhydrite binders.

Physical and technical properties of the activated fluoroanhydrite-based composition:

- setting time: start -2 hours, finish -4 hours;

- compressive strength at the age of 28 days $28-40 \mathrm{MPa}$;

- bending strength at the age of 28 days $-10 \mathrm{MPa}$;

- softening coefficient $\mathrm{Cs}=0.71$.

The described above characteristics of the physical and technical properties of the developed calcium sulfate-based composition suggest that it can be a substitute for building gypsum. Given the low cost of fluoroanhydrite, it is possible to talk about significant economic efficiency when using it and reducing the environmental load in fluoroanhydrite disposal sites.

The developed composition based on activated fluoroanhydrite can be used in the casting production of architectural and finishing products as a cheap and high-strength substitute for gypsum binder. 


\section{Conclusions}

The conducted studies of the structure, composition, and properties of the high-strength fluoroanhydrite composition established the influence of sodium phosphate on the processes of structure formation and to justify the increase in the physical and mechanical characteristics.

Using the solution of sodium phosphate for tempering the man-made binder intensifies the processes of fluoroanhydrite hydration. This is confirmed with the shortened setting time, formation of a denser, water resistant and more durable material. Therefore, in comparison with traditional gypsum and anhydrite materials, the developed composition can replace traditional gypsum binders.

\section{Acknowledgements}

Financial supports from the Kalashnikov Izhevsk State University [08.04.01/18 YGI] is gratefully acknowledged and Financial supports from the Kalashnikov State University (08.06.01/18YGI) is gratefully acknowledged.

\section{References}

Altmann, H.-D. (1993). Anhydrit baustoffe. Fließestricheaus Calciumsulfat-Bindemitteln. Estrich-Technik, 12, 26-34.

Belov, V. V., Buryanov, A. F., Yakovlev, G. I., Petropavlovskaya, V. B., Fischer, H.-B., \& Mayeva, I. S. (2012). Modification of structure and properties of construction composites on the basis of calcium sulfate (Monograph). A. F. Buryanov (Ed.). Moscow: Publishing house De Nova. 196 p.

Budnikov, P. P., \& Zorin, P. S. (1954). Anhydrite cement. M.: The state publishing house of literature on construction materials. $92 \mathrm{p}$.

El Hajjouji, A., \& \& Murat, M. (1989). Zusammenhang zwischen Porengefüge und Festigkeit abgebundener Gipspasten. Einfluß chemischer Zusätze. ZKG INTERNATIONAL, 42(8), 419-424.

Fischer, H.-B., \& Vtorov, B. (2000). Influence of activators on natural anhydrite properties. In II International Meeting on Chemistry and Technology of Cement (vol. 2, pp. 53-61). Mendeleev University of Chemical Technology, Moscow, Russia.

Grimme, H. (1962). In Mittel deutschland entwickelte Anhydrit binderarten. Zement-Kalk-Gips, Nr. 7.

Jakowlew, G., \& Keriene, J. (2000, September). Fluoranhydrit verb und werkstoffe fuer den Fliessestrich. In 14 Internationale Baustofftagung "Ibausil” (Band 2, pp. 871-879). Weimar, Germany.

Leškevičienè, V., \& Nizevičienè, D. (2014). Influence of the setting activators on the physical mechanical properties of phosphoanhydrite. Chemical Industry and Chemical Engineering Quarterly, 20(2), 233-240. https://doi.org/10.2298/CICEQ121127004L

Lushnikova, E. S., Ruzina, N. S., Gordina, A. F., \& Polyanskih, I. S. (2016, December). Composite materials based on sulfur wastes. In Materials of II Bryansk's International Innovative Forum “CONSTRUCTION-2016” (vol. 1, pp. 75-78). Bryansk.

Nowak, S., Wutz, K., Prosiegel, K., \& Fischer, H.-B. (2006, September). Zum Einsatz von Melaminharzen in Calciuumsulfat Fließestrichen. In 16 Internationale Baustofftagung "Ibausil” (Band 1, pp. 857-866). Weimar, Germany.

Ottemann, J. (1951). Über Ergebnisse und Probleme der Anhydrit forschung. Silikat-technik, 2(1), 5-9.

Plekhanova, T. A., Keriene, Ja., Gailius, A., \& Yakovlev, G. I. (2007). Structural, physical and mechanical properties of modified wood-magnesia composite. Construction and Building Materials, 21(9), 1833-1838. https://doi.org/10.1016/j.conbuildmat.2006.06.029

State Standard Union SSR. (1979). Gypsum binder. Test methods (GOST 23789-79).

State Standard Union SSR. (1985). Wall materials. Methods of determination of strength at compression and a bend (GOST 8462-85).

The neutralized withdrawal of production of fluoric hydrogen (ftorangidrit). Specifications. Certificate № 921/2/124398 (TS 5744-132-05807960-98). (1998). Ftorangidrit. HaloPolymer company, Russia, Perm.

Vlad, D., Zouaoui, N., Kambia, M., \& Plank, J. (2006, September). Zur Wechselwirkung von Polycarboxylat - Flie $\beta$ mitteln mit sulfatisch angeregtem REA-Anhydrit. In 16 Internationale Baustofftagung "Ibausil” (Band 1, 759-766). Weimar, Germany.

Volzhensky, A. V., Burov, U. S., \& Kolokolnikov, V. S. (1979). The mineral binders: (technology and properties). Moscow: Stroyizdat. $477 \mathrm{p}$.

Vtorov, B., \& Fisher, H.-B. (2001). Optimization of anhydrite structure - Modeling and optimization in materials science. In Materials for 40 th International Seminar on Modeling and Optimization of Composites (pp. 66-67). Odessa.

Vtorov, B., Fischer, H.-B., \& Stark, J. (2000, September). Zur Anregung von Naturanhydrit. In 14 Internationale Baustofftagung "Ibausil" (Tagungsband 1, pp. 1069-1082). Weimar, Germany. 